\title{
ETHzürich
}

ETH Library

\section{Comparing the limit equilibrium method and the numerical stress analysis method of tunnel face stability assessment}

\section{Conference Paper}

Author(s):

Perazzelli, Paolo; Anagnostou, Georg

Publication date:

2011-05

Permanent link:

https://doi.org/10.3929/ethz-a-010817186

Rights / license:

In Copyright - Non-Commercial Use Permitted 


\title{
Comparing the limit equilibrium method and the numerical stress analysis method of tunnel face stability assessment
}

\author{
P. Perazzelli \\ Dept. of Struct. and Geotech. Eng., Sapienza University, Rome, Italy \\ G. Anagnostou \\ ETH Zurich, Switzerland
}

\begin{abstract}
The aim of this work is to compare two approaches for evaluating the stability of a tunnel face that is reinforced by bolts: the limit equilibrium method of Anagnostou \& Serafeimidis (2007) and the numerical stress analysis method. The comparative calculations have been carried out in respect of a dry cohesive - frictional soil. The numerical solutions were obtained by employing the finite difference code FLAC3D assuming an elastic, perfectly plastic material obeying the Mohr-Coulomb yield criterion. The paper starts with the relatively simple case of an unreinforced tunnel face, comparing the model predictions concerning the necessary support pressure and discussing the influence of tunnel shape, in situ stress and dilatancy. The calculations show that the limit equilibrium method and the numerical stress analysis method provide results which are close to those obtained by other existing analysis methods. The second part of the paper investigates the reinforcing effect of the bolts. The numerical stress analysis method shows clearly that shear failure of the soil around the bolts governs the bolt-soil interaction ahead of the face, suggesting that the bond strength (i.e. the resistance of the interface between grouted bolt and soil) to be used in the limit equilibrium methods should take due account of the shear resistance of the ground and thus the normal stresses prevailing in the core ahead of the face. As shown in the paper, this can be done reasonably well by means of a simplified procedure.
\end{abstract}

\section{INTRODUCTION}

When tunnelling through low strength ground the stability of the excavation face is a major concern for the geotechnical engineer. In mechanized tunnelling, closed shields are applied for stabilizing the face. In conventional tunnelling, several techniques could be applied: ground reinforcement of the excavation face by bolts, partial excavation, ground improvement by grouting or artificial freezing. Face reinforcement is a popular solution because of its relatively low cost, its great flexibility and its adaptability to local geological conditions. The bolts are installed on the face with a distribution that depends on the stratigraphy and quality of the encountered ground and are removed as the excavation advances. Fiberglass bolts are often employed because - besides having a high tensile strength - they exhibit brittle behaviour, which is favourable for the excavation process.
Many researchers have studied the stabilizing effect of face bolts through spatial numerical stress analyses. Peila (1994) performed 3D FEM computations which illustrated that reinforcement reduces the deformations and the plastic zone in the core ahead of the face, while the installation of a lining limits the plastic zone and the radial displacements around the tunnel. $\mathrm{Ng}$ \& Lee (2002) performed parametric 3D FEM analyses to study the influence of the axial stiffness of the bolts with respect both to the stability of the tunnel heading and surface settlement in stiff clay. Yoo \& Shin (2003) studied the effect of several reinforcing parameters (spacing, length and axial stiffness) on stability, both for cohesive and cohesive-frictional soil and for different cover-to-diameter ratios. Dias \& Kastner (2005) investigated - by means of $3 \mathrm{D}$ finite difference analyses - the behaviour of a reinforced face of a deep tunnel in soft rock for different bolt spacings and different assumptions concerning the interface between the grouted bolt and the surrounding soil (perfect adherence or finite bond strength). Furthermore, 
they compared the numerical results obtained from a model that took account of each bolt individually with the results of simplified numerical analyses, where the effect of bolting is taken into account either by introducing an equivalent face support pressure or by increasing the cohesion of the core. Kavvadas and Prountzopoulos (2009) performed 3D FEM analyses in order to find out the optimum bolt length and the equivalent face support pressure for different soil shear strength parameters and cover-todiameter ratios.

For practical engineering purposes, a 3D numerical stress analysis is a heavy and time consuming method. It is also an unnecessarily complex way (actually a long way round) if it is only the stability of the face (but not the deformations of the ground) that is concerned. Simpler approaches, like the limit equilibrium methods (Cornejo,1989; Anagnostou \& Kovári, 1994; Broere, 1998; Anagnostou \& Serafeimidis, 2007), or methods based on plasticity theorems (Leca \& Dormieux, 1990, Mandel \& Halphen, 1974; Caquot \& Kerisel, 1956) are typically used for this purpose. These methods take into account the reinforcing effect of the bolts either by introducing support forces or by assuming a higher cohesion for the ground.

The present paper investigates the stability of the reinforced tunnel face in cohesive-frictional soils by means of 3D numerical stress analyses. More specifically, for a given soil friction angle, tunnel geometry and depth of cover, the minimum soil cohesion needed for equilibrium is calculated numerically for different bolting densities and compared with the results obtained by the limit equilibrium method of Anagnostou \& Serafeimidis (2007). The investigation consists of two phases: (i) in the first phase, the comparison is performed in terms of the face support pressure at limit equilibrium, i.e. by means of a simplified numerical model that does not consider any bolt individually; (ii) the satisfactory results of the first phase encouraged the Authors to continue the comparative analyses with a complex model of reinforcement, which takes account of individual bolts and their interaction with the surrounding soil.

\section{INVESTIGATED PROBLEM}

We consider a square, $100 \mathrm{~m}^{2}$ big tunnel face excavated through homogeneous soil at a depth of $23 \mathrm{~m}$ (Fig. 1). The choice of the unusual square shape is due to the aim of the work: the comparison between the numerical analysis and the limit equilibrium method of Anagnostou \& Serafeimidis (2007), which is based upon the simplified model of a rectangular face. However, in order to investigate whether the assumption concerning the face shape affects the results of the stability analysis signifi- cantly, numerical calculations were carried-out also for a more realistic geometry (Fig. 1).

A low-strength, cohesive-frictional ground and dry conditions are considered. All calculations were carried-out for a friction angle $\varphi^{\prime}$ of $25^{\circ}$, a unit weight $\gamma$ of $17 \mathrm{kN} / \mathrm{m}^{2}$ and cohesion values $c$ ' between 0 and $15 \mathrm{kPa}$. Specifically for the stress analysis, assumptions have to be made concerning the initial stress field and the deformability of the ground. The parameters can be found in Table 1 . The influence of the angle of dilatancy $\psi$ and of the coefficient of earth pressure at rest $k_{0}$ was numerically investigated only for the simplified numerical model, which considers a face support pressure instead of the individual bolts.
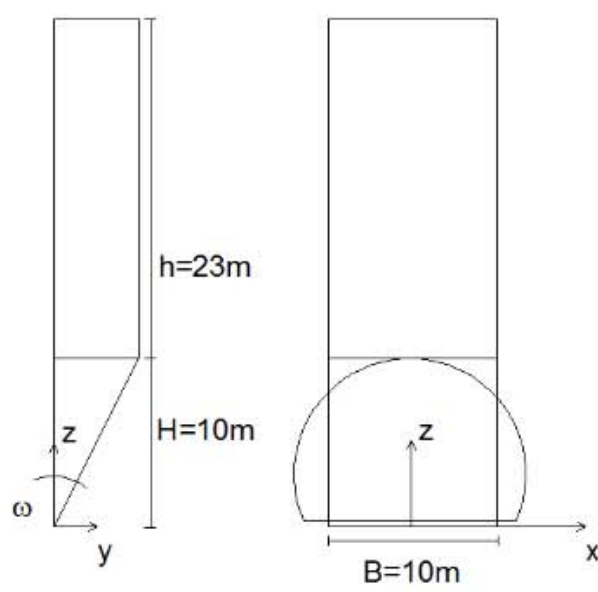

Figure 1. Failure mechanism with square face after Anagnostou \& Serafeimidis (2007) and non-square face of equivalent area.

Table 1. Geotechnical parameters of the investigated problem

\begin{tabular}{lr} 
Soil & \\
\hline Unit weigth $\gamma\left[\mathrm{kN} / \mathrm{m}^{3}\right]$ & 17 \\
Young modulus $E^{\prime}[\mathrm{MPa}]$ & 400 \\
Poisson ratio $v$ & 0.3 \\
Friction angle $\varphi^{\prime}\left[{ }^{\circ}\right]$ & 25 \\
Cohesion $c^{\prime}[\mathrm{kPa}]$ & $0-15$ \\
Dilatation angle $\psi^{\prime}\left[{ }^{\circ}\right]$ & 0 or $10^{*}$ \\
Initial State & \\
Litostatic stress distribution & \\
Coefficient of earth pressure at rest $k_{0}$ & \\
\hline * used only in the analysis of the unreinforced face &
\end{tabular}

\section{LIMIT EQUILIBRIUM METHOD}

The computational method of Anagnostou \& Serafeimidis (2007) is based upon a failure mechanism that consists of a wedge and the overlying prism (Fig. 1). The critical inclination $\omega$ of the inclined slip plane is determined iteratively so that it maximizes the support requirements. The method represents an improvement of the model of Anagnostou \& Kovári (1994) in that it eliminates the need for an a priori 
assumption of the distribution of the vertical stress $\sigma_{z}$ in the wedge and offers the possibility of analyzing a layered ground with an arbitrary distribution of reinforcement.

The stabilizing effect of the bolts is considered as a support pressure $s$ given by:

$s=n \cdot \min \left[F_{z}, \max \left(\pi d \tau_{m} a, F_{p}\right), \pi d \tau_{m}\left(L^{\prime}-a\right)\right]$,

where $n$ denotes the reinforcement density (e.g., number of bolts per sqm), $F_{z}$ is the tensile strength of the bolt, $\tau_{m}$ is the bond strength at the soil - grout interface, $d$ is the grouted borehole diameter, $a$ is the bond length inside the wedge and $L^{\prime}$ denotes the actual bolt length. Note that the bond lengths $a$ and $\left(L^{\prime}-a\right)$ vary over the height of the wedge and, moreover, they depend also on the specific mechanism considered, i.e. on the angle $\omega$. Consequently, the support force offered by the reinforcement will not be uniformly distributed even in the case of constant bolt spacing (Fig. 2).

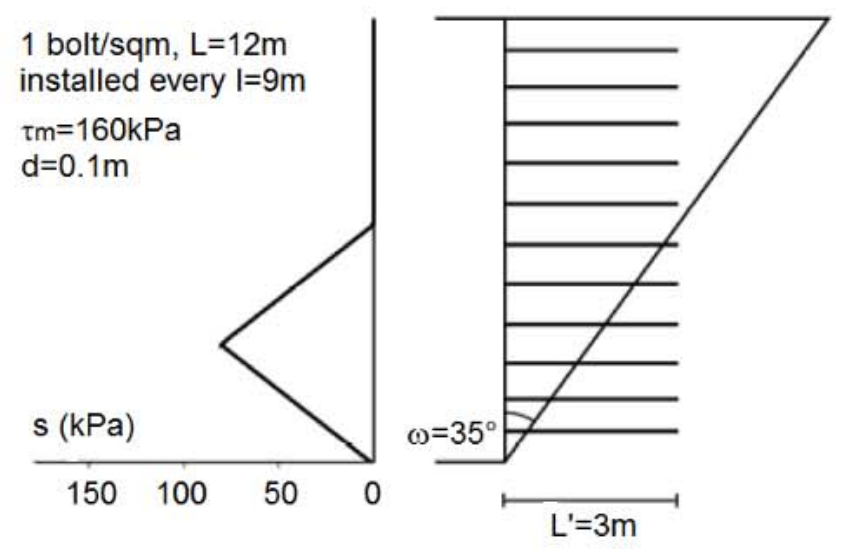

Figure 2. Example of support pressure distribution in the limit equilibrium method of Anagnostou \& Serafeimidis (2007).

In the present paper, the method is employed firstly assuming that the support pressure $s$ is uniform, i.e. without considering the reinforcement peculiarities (Section 4). Subsequently, in the calculations considering a reinforcement, the needed bolting density is determined as a function of the soil cohesion for fixed values of the parameters $d, L^{\prime}$ and $\tau_{m}$ (Section $5)$.

\section{STRESS ANALYSIS OF THE UNREINFORCED TUNNEL FACE}

\subsection{Numerical model}

The stress analyses were performed by the $3 \mathrm{D}$ finite difference code FLAC3D Vers. 4.1. The ground is modeled as an elastic, perfectly plastic material obeying the Mohr-Coulomb yielding criterion and a non-associated plasticity flow rule. The relevant geotechnical parameters are reported in Table 1; two values of the coefficient of earth pressure at rest $k_{0}$, 0.57 and 0.7 , are considered.

Due to the vertical symmetry plane, only one half of the entire domain needs to be discretised. Figure 3 shows the dimensions of the computational domain, which consists approximately of 75000 nodes and 69000 zones. The displacements of the vertical model boundaries parallel and perpendicular to the tunnel axis are fixed in the direction $x$ and $y$, respectively. All displacement components are fixed at the bottom model boundary.

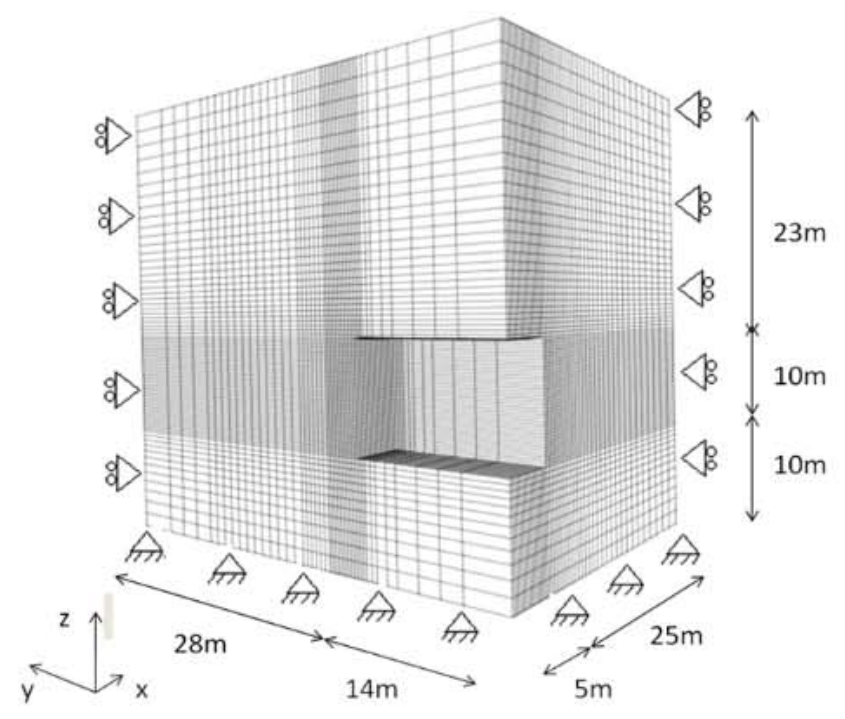

Figure 3. Computational domain and boundary conditions.

In order to avoid rather secondary effects and to focus directly to the tunnel face behavior, the details of the excavation and support sequence are not simulated. Instead a simplified excavation scheme is adopted, where the position of the tunnel face remains fix in the model and the excavation process is simulated by a gradual reduction of the longitudinal stress acting on the face. The tunnel support is considered rigid and extends up to the face. The analysis consists of the following steps: (i) initialization of the in situ stress, considering a lithostatic distribution; (ii) removal of the brick elements representing the excavated tunnel volume, fixing of the gridpoints on the tunnel boundaries and calculation of the reaction grid-point forces; (iii) replacement of the restraint conditions for the grid-points on the face by support forces equal to the reactions; (iv) gradual reduction of the support forces at the face gridpoints, equivalent to a reduction of the original horizontal stress by a factor, which is constant along the face. 


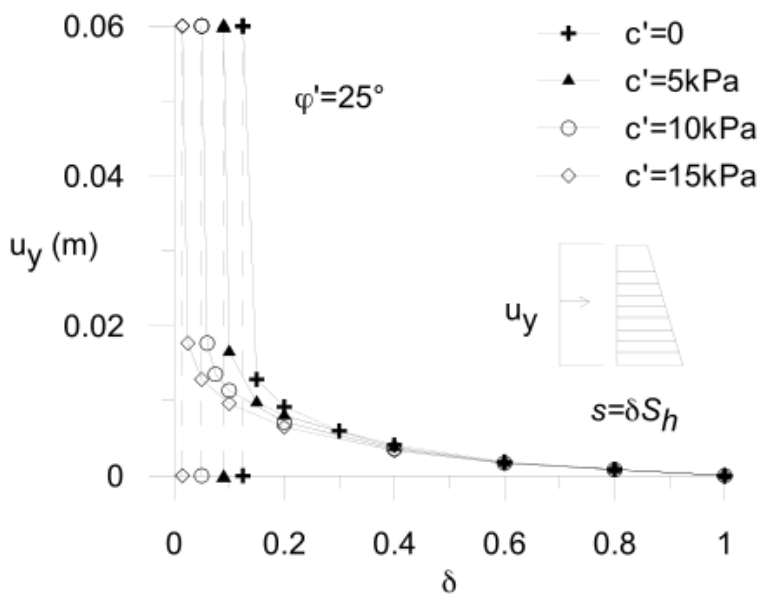

Figure 4. Longitudinal displacement at the center of the face as a function of the normalized support pressure (square tunnel face, $\left.k_{0}=0.57, \psi=0\right)$.

Table 2. Stress analysis results for unreinforced face

\begin{tabular}{|c|c|c|c|c|c|c|}
\hline Geom $^{*}$ & $\begin{array}{c}\psi \\
{\left[^{\circ}\right]}\end{array}$ & $\begin{array}{l}k_{0} \\
{[-]}\end{array}$ & $\begin{array}{c}c^{\prime} \\
{[\mathrm{kPa}]}\end{array}$ & $\begin{array}{c}\delta_{\text {equitl }} \\
{[-]}\end{array}$ & $\begin{array}{c}\delta_{\text {non-equil }} \\
{[-]}\end{array}$ & $\begin{array}{c}\mathrm{s}_{\text {lim }} \\
{[\mathrm{kPa}]}\end{array}$ \\
\hline$Q$ & 0 & 0.57 & 0 & 0.150 & 0.1250 & 37.80 \\
\hline$Q$ & 0 & 0.70 & 0 & 0.125 & 0.1000 & 37.49 \\
\hline$Q$ & 10 & 0.57 & 0 & 0.125 & 0.1000 & 30.93 \\
\hline$C$ & 0 & 0.57 & 0 & 0.125 & 0.1000 & 31.65 \\
\hline$Q$ & 0 & 0.57 & 5 & 0.100 & 0.0900 & 26.12 \\
\hline$Q$ & 0 & 0.70 & 5 & 0.080 & 0.0600 & 23.32 \\
\hline$Q$ & 10 & 0.57 & 5 & 0.080 & 0.0600 & 19.25 \\
\hline$C$ & 0 & 0.57 & 5 & 0.090 & 0.0800 & 23.91 \\
\hline$Q$ & 0 & 0.57 & 10 & 0.060 & 0.0500 & 15.12 \\
\hline$Q$ & 0 & 0.70 & 10 & 0.050 & 0.0250 & 12.50 \\
\hline$Q$ & 10 & 0.57 & 10 & 0.050 & 0.0250 & 10.31 \\
\hline$C$ & 0 & 0.57 & 10 & 0.050 & 0.0400 & 12.66 \\
\hline$Q$ & 0 & 0.57 & 15 & 0.025 & 0.0150 & 5.50 \\
\hline$Q$ & 0 & 0.70 & 15 & 0.025 & 0.0125 & 6.25 \\
\hline$Q$ & 10 & 0.57 & 15 & 0.025 & 0.0125 & 5.15 \\
\hline$C$ & 0 & 0.57 & 15 & 0.010 & 0.0050 & 2.11 \\
\hline
\end{tabular}

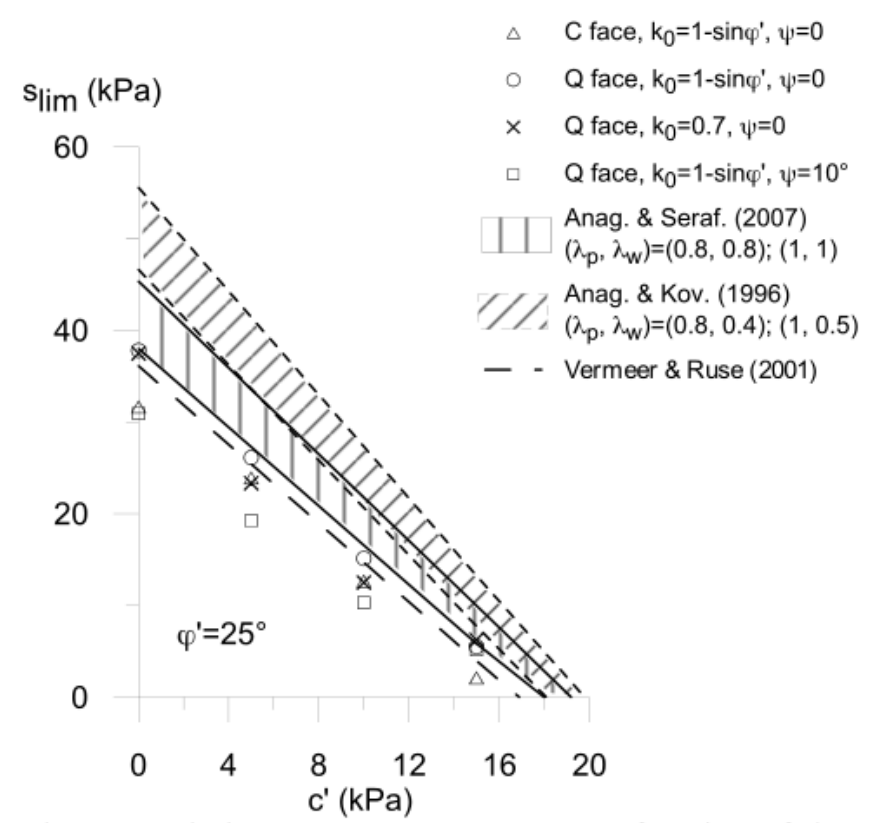

Figure 5. Limit support pressure $s_{\text {lim }}$ as a function of the soil cohesion for $\phi^{\prime}=25^{\circ}$ according to different methods.

\subsection{Face stability criterion}

The common way to investigate the face stability is to evaluate the relation between the longitudinal displacement of a control point of the face (here, the center of the face) and the applied support pressure normalized by the initial horizontal stress (Vermeer \& Ruse, 2001). The instability is represented by the asymptotic increase of the displacement to infinity, when the face support pressure approaches the limit value.

Figure 4 shows examples of this relation for a particular parameter set. The left end of each curve indicates the minimum pressure, for which equilibrium was achieved, and represents an upper bound of the limit pressure. The vertical dashed lines show the values of the face support pressures, for which an equilibrium was not found, and indicate a lower bound of the limit pressure. As the difference between two bounds is very small, the limit support pressure $s_{\text {lim }}$ was calculated as the mean value of the two bounds.

\subsection{Results}

Table 2 contains the results of all performed calculations, while Figure 5 shows the relationship between the limit support pressure and the cohesion according to the results of the numerical analyses under different assumptions concerning $k_{0}$-value, dilatancy angle $\psi$ and face shape (single marked points). The diagram includes for the purpose of comparison the numerical results of Vermeer \& Ruse (2001), which concern a circular face of equivalent area, and the results of the limit equilibrium analyses after Anagnostou \& Serafeimidis (2007) and Anagnostou \& Kovári (1996) for coefficients of lateral stress $\lambda$ of 0.80 or 1 . Our numerical results are close to those of Vermeer \& Ruse (2001) and confirm their conclusion, that the influence of $k_{0}$-value on the limit support pressure is negligible. A higher dilatancy angle increases only slightly face stability. The differences between the square and the other, more realistic tunnel shapes are very small. The limit equilibrium method of Anagnostou \& Kovári (1996) overestimates the necessary support pressure. The limit equilibrium method of Anagnostou \& Serafeimidis (2007) gives results very close to those of the stress analysis particularly for $\lambda=1$, i.e. for the value proposed by Terzaghi and Jelinek (1954). The value of $\lambda=0.8$ (suggested by the model tests of Melix, 1987, and adopted by Anagnostou and Kovári, 1996, for elaborating design nomograms) is on the safe side.

Figure 6 compares the limit support pressures obtained by several methods for the case of a cohesionless soil. For lower values of friction angle $\left(\varphi^{\prime}=20\right.$ $25^{\circ}$ ), the solution of Anagnostou \& Serafeimidis (2007) is located between the lower bound solution of Leca \& Dormieux (1990) and upper bound solu- 
tions of Mandel \& Halphen (1974) and Caquot \& Kerisel (1956). The predictions of Anagnostou \& Kovári (1996) are close to the upper bound solutions. At higher values of the friction angle, the differences between all these methods became negligible and the model predictions are close to experimental results (centrifuge modeling). The results of the FLAC3D calculation of Figure 5 are closer to the solution of Vermeer \& Ruse (2001) and Leca \& Dormieux (1990).

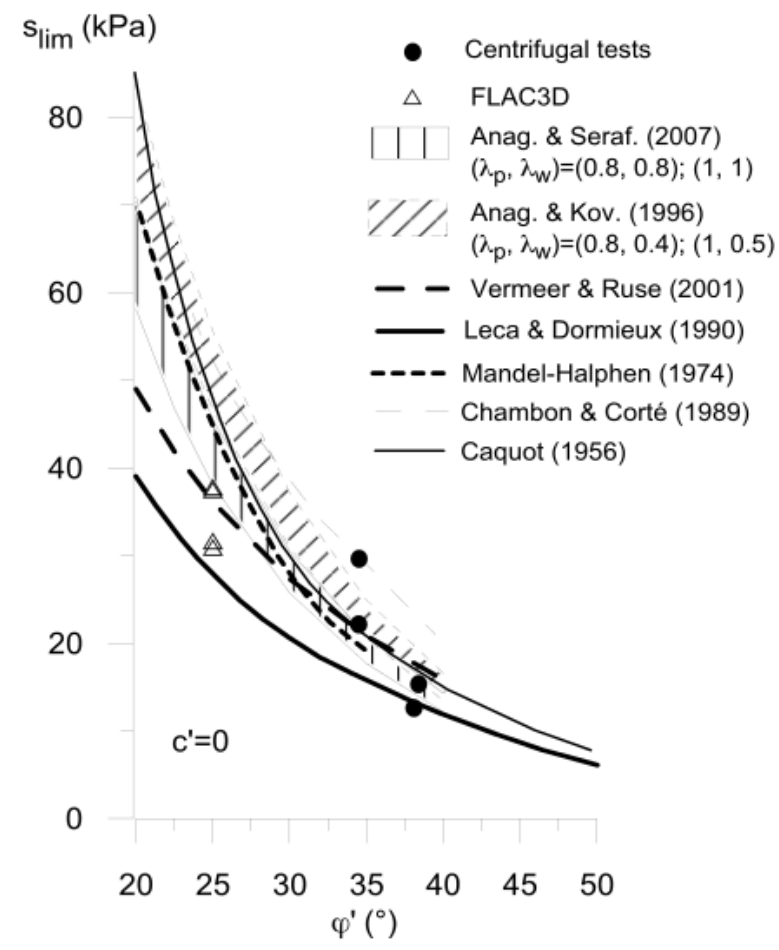

Figure 6. Limit support pressure $s_{\text {lim }}$ as a function of the soil friction angle for $c^{\prime}=0$ according to different methods (diagram after Ribacchi 1993).

In conclusion, in the simpler case of an unreinforced face, the results obtained after Anagnostou \& Serafeimidis (2007) are absolutely close to the predictions of stress analysis and comparable with other existing methods.

\section{STRESS ANALYSIS OF THE REINFORCED TUNNEL FACE}

\subsection{Computational model}

The numerical analysis of the reinforced face was performed for the same geometrical and geotechnical parameters as in the last Section (Table 1). On account of the main objective of the present work (the comparison with the limit equilibrium method) and also of the small effect of face geometry, only the square face was investigated.
The bolts were modeled individually using the "cable" element in the FLAC3D code. This structural element behaves like an elastic, perfectly plastic material that may yield in tension but cannot resist a bending moment. The assumed Young modulus $E_{b}$ and cross-sectional area $A_{\mathrm{b}}$ of the cable elements (Table 3) are typical for fiberglass pipes. The tensile strength of the cable was taken infinite, i.e. bond failure is the only failure mechanism considered. The reason for this modeling decision is that we want to focus to the effect of the grouted bolt - soil interface.

Table 3. Parameter values of the grouted bolt model

\begin{tabular}{llcl}
\hline Cable elements & & & \\
\hline Length & $L^{\prime}[\mathrm{m}]$ & 7 & \\
Area & $A_{b}\left[\mathrm{~m}^{2}\right]$ & 0.00785 & \\
Young modulus & $E_{b}[\mathrm{GPa}]$ & 20 & \\
Interface cable-grid & & & \\
\hline Borehole diameter & $d[\mathrm{~m}]$ & 0.1 & \\
Shear stiffnes & $K_{\text {int }}[\mathrm{GPa}]$ & 10 & \\
Strength & $\tau_{m}=$ otan $\varphi_{\text {int }}+c_{\text {int }}$ & $(\mathrm{i})^{*}$ & $(\mathrm{ii})$ \\
& $c_{\text {int }}[\mathrm{kPa}]$ & 160 & $c^{\prime}$ \\
& $\varphi_{\text {int }}\left[{ }^{\circ}\right]$ & 0 & $\varphi^{\prime}=25^{\circ}$ \\
\hline \multirow{2}{*}{ Only in Section 5.2} & & \\
\end{tabular}

Table 4. Stress analysis results for reinforced face (stressdependent bond strength)

\begin{tabular}{cccc}
\hline$n$ & $\begin{array}{c}c_{\text {equil }}^{\prime} \\
{[\mathrm{kPa}]}\end{array}$ & $\begin{array}{c}c_{\text {non-equil }}^{\prime} \\
{[\mathrm{kPa}]}\end{array}$ & $\begin{array}{c}c^{\prime}{ }_{\text {lim }} \\
{[\mathrm{kPa}]}\end{array}$ \\
\hline 0.36 & 14 & 12 & 13 \\
1.00 & 12 & 10 & 11 \\
1.44 & 10 & 8 & 9 \\
1.96 & 7 & 5 & 6 \\
\hline
\end{tabular}

Since the cable elements are fully grouted, the force developing along its length is the response to relative motion between the cable and the grid. The numerical formulation of the interface between the structural element and the grid, which represents conceptually the interface between soil and grouted bolt, is incorporated in the numerical formulation of the structural element. The code allows for an elastoplastic interface model defined by the stiffness $K_{\mathrm{int}}$, perimeter $p_{\text {int }}$ and shear strength parameters $c_{i n t}$ and $\varphi_{\text {int }}$. The present work assumes practically rigidplastic interface behavior, i.e. a high value of the interface stiffness $K_{\text {int }}$, (Table 3). Concerning the bond strength the assumption was made that it depends on the confining stress according to MohrCoulomb criterion with strength parameters equal to those of the soil ("stress-dependent bond strength"). For the purpose of comparison (Section 5.2), also a simplified model ("constant bond strength") considering a shear resistance of $\tau_{m}=160 \mathrm{kPa}$ was considered (Table 3 ). Such a value corresponds to the 
bond strength of a loose to medium dense sand at a depth of more than $4 \mathrm{~m}$ (Ostermayer, 1991).

The bolt length $L^{\prime}$ is taken equal to $0.7 \mathrm{H}$, i.e. 7 $\mathrm{m}$. (This value is, for example, equal to the minimum length of initially $12 \mathrm{~m}$ long bolts overlapping by $5 \mathrm{~m}$.) The bolts are horizontal and uniformly distributed on the face on a rectangular grid. Four different bolting patterns were investigated, consisting of $3 \times 6,5 \times 10,6 \times 12$ or $7 \times 14$ bolts in the modeled half face and corresponding to bolt densities $n$ of $0.36,1$, 1.44 and $1,96 \mathrm{~m}^{-2}$, respectively.

In order to simulate better the behavior of the soil between the bolts in the case of high bolting density, a finer mesh is adopted than in the numerical model for the unreinforced face (Fig. 3): the size of the square brick elements, which discretize the face, is here $0.125 \mathrm{~m}$ instead of $0.25 \mathrm{~m}$ in the previous mesh. The excavation process was simulated as described in Section 4.1.

For each bolting pattern the face stability was investigated for a series of closely spaced cohesion values in order to determine an upper and a lower bound of the minimum cohesion needed for stability for the given bolting pattern (Table 4). The limit cohesion $c^{\prime}{ }_{l i m}$ was taken as the mean value of these bounds (last column of Table 4). The black circular markers in Figure 10 show the relationship between limit cohesion $c^{\prime}$ lim and bolt density $n$ calculated in this way. They will be compared to the limit equilibrium predictions in Section 5.3. But before doing this the issue of bolt - soil interface modeling will be addressed.

\subsection{On the assumption about the bond strength}

This section compares the results obtained when assuming a stress-dependent bond strength with the results for a constant bond strength considering the case of a face reinforcement by $6 \times 12$ bolts (bolt density $n=1.44 \mathrm{~m}^{-2}$ ). The two analyses provide close values of limit soil cohesion: $c^{\prime}{ }_{\text {lim }}=6-8 \mathrm{kPa}$ in the case of a constant bond strength $\tau_{m}$ of $160 \mathrm{kPa}$ and $8-10 \mathrm{kPa}$ in the case of a stress-dependent bond strength. As can be seen from Figure 7, however, relevant differences exist concerning the soil bolt interaction close to limit equilibrium.

In the case of a constant bond strength $\left(\tau_{m}=160\right.$ $\mathrm{kPa}, c^{\prime}=8 \mathrm{kPa}$ ), the contour lines of longitudinal displacement and the extrusion profile show clearly big gradients in the vicinity of the bolts (Fig. 7a). At the grout - soil interface the soil displacement is practically zero because the shear stress does not reach the bond strength of $160 \mathrm{kPa}$ and a perfect adherence is preserved at the interface, while the surrounding soil fails. So, shear failure occurs not exactly at the interface (this is not possible due to the assumed high bond strength) but within the soil close to the interface. The soil flows around the grouted bolt, thus "by-passing" the constraint imposed by the assumed high bond strength.

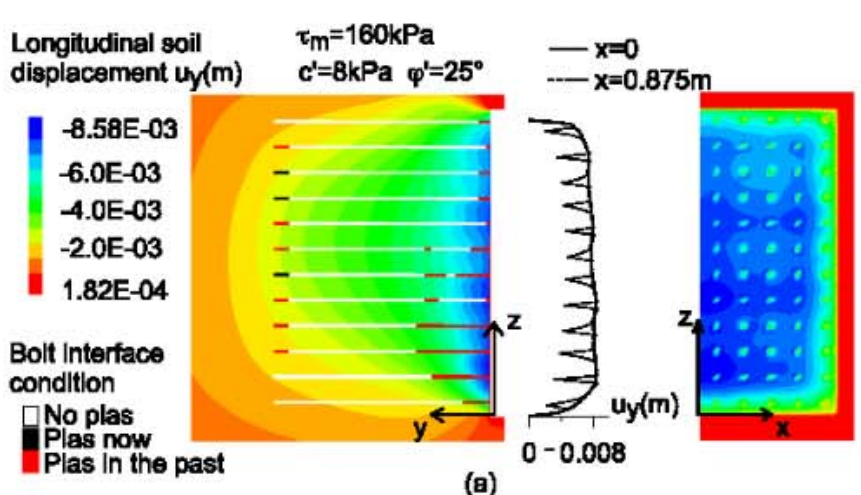

(a)

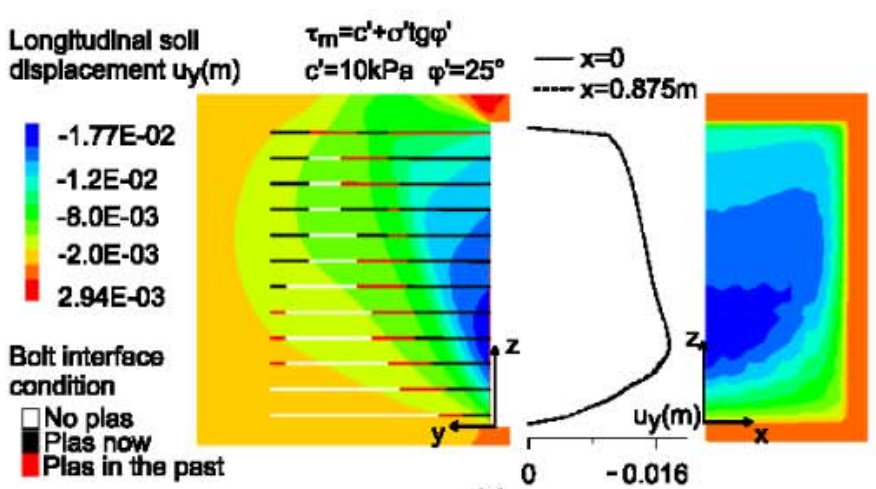

(b)

Figure 7. Extrusion profiles of the face, contour lines of the soil longitudinal displacement and bolt interface condition for the upper bound of the limit cohesion (i.e., for the minimum considered cohesion satisfying equilibrium): (a) constant bond strength $\tau_{m}=160 \mathrm{kPa}$ (results for $c^{\prime}=8 \mathrm{kPa}$ and $\mathrm{n}=1.44$ bolts $/ \mathrm{m}^{2}$ ); (b) stress-dependent bond strength $\tau_{m}=\sigma \tan \varphi^{\prime}+c^{\prime}$ (results for $c^{\prime}=10 \mathrm{kPa}$ and $\mathrm{n}=1.44$ bolts $/ \mathrm{m}^{2}$ ).

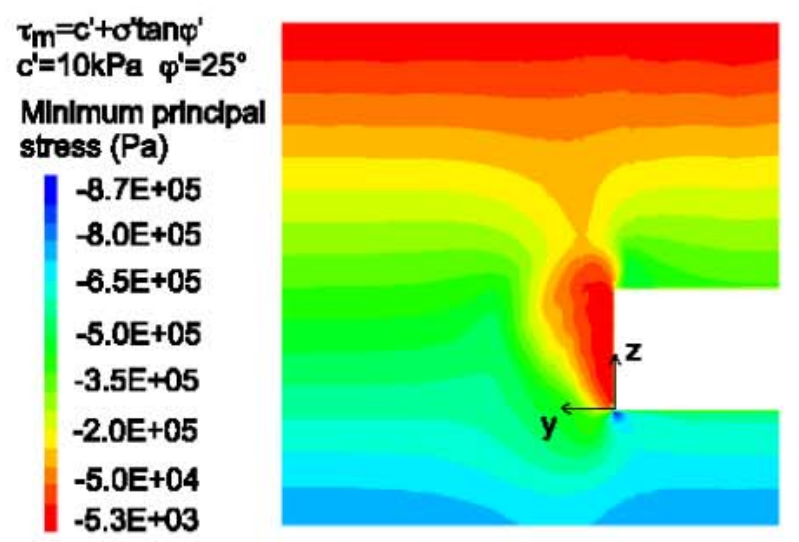

Figure 8. Contour lines of the minimum principal stress (compressive stresses are negative) in the vertical symmetry plane for the upper bound of the limit cohesion (i.e., for the minimum considered cohesion satisfying equilibrium) assuming a stressdependent bond strength $\tau_{m}$ of $\sigma \tan \varphi^{\prime}+c^{\prime}\left(n=1.44\right.$ bolts $\left./ \mathrm{m}^{2}\right)$

In the case of the stress-dependent bond strength, shear failure occurs at the grout - soil interface resulting in a discontinuity of the displacements of soil and bolts, in a smooth extrusion profile and in larger longitudinal displacements (Fig. 7b). The bond failure observed in this case is due to the low bond 
strength in the ground close to the face: The bond strength is low overthere because it depends on the confining stress, which decreases strongly in the vicinity of the face due to the soil plastification associated with the axial stress release (Fig. 8).

These results indicate that the simplifying assumption of a constant bond strength (which is often made in limit equilibrium analyses) should take due account of the strength parameters of the soil and of the stress level in the core ahead of the face.

\subsection{Comparison with limit equilibrium method}

The lowest curve in Figure 10 shows the necessary bolt density $n$ as a function of the soil cohesion according to the limit equilibrium method of Anagnostou \& Serafeimidis (2007) and assuming a constant bond strength $\tau_{m}$ of $160 \mathrm{kPa}$. The numerical stress analyses (black markers) lead to considerably higher reinforcement densities than predicted by the limit equilibrium method. This is true not only for the stress-dependent bond strength FLAC3D model (black circles), but also for the numerical model assuming a constant bond strength (single triangle) of $160 \mathrm{kPa}$ - the same value as in the limit equilibrium analysis. The reason is that in the stress analysis the soil flows around the grouted bolt irrespectively of the practically perfect bond that was assumed specifically for the grout - soil interface (see last Section). The significant overestimation of the reinforcing effect of the bolts is due to the assumed bond strength $\tau_{m}$, which as discussed in last section, is not consistent with the resistance of the surrounding soil to shearing. The bond strength in a cohesive - frictional material should consider the shear strength parameters of the soil and the confining stress on the bolts as the later influences the frictional resistance.

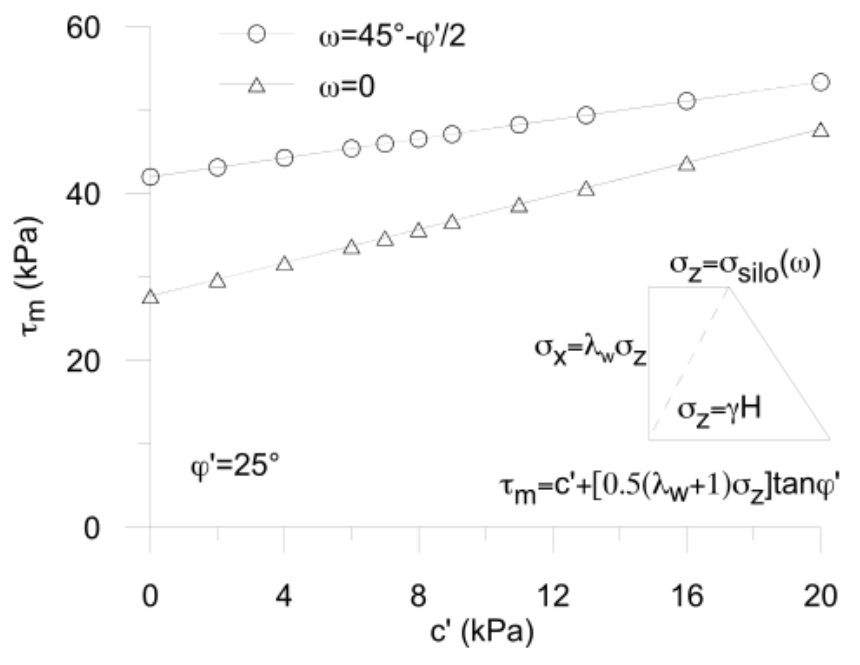

Figure 9. Bond strength $\tau_{m}$ determined based upon the shear strength parameters of the soil and assuming a trapezoidal confining stress distribution according to Anagnostou \& Kovári (1994).
A consistent assumption about the confining stress (and finally about the bond strength $\tau_{m}$ ) can be made by considering the stress distribution in the ground within the wedge. Following Anagnostou \& Kovári (1994), we assume that the ratio $\lambda_{w}$ of the horizontal to the vertical stress $\sigma_{x} / \sigma_{z}$ is constant, while the vertical stress $\sigma_{z}$ changes linearly from $\gamma H$ in the tunnel floor to the silo pressure at the top of the wedge (see inset of Fig. 9). The confining stress needed for the calculation of the bond strength is taken equal to the mean stress $0.5\left(1+\lambda_{w}\right) \sigma_{z}$. For simplicity, a constant bond strength is assumed in the limit equilibrium analysis based upon the average vertical stress, i.e. the stress $\sigma_{z}$ in the centre of the face. As suggested by Anagnostou and Kovári (1994) and as assumed also for the computation of the nomograms of Anagnostou and Serafeimidis (2007), the value of $\lambda_{w}$ is taken equal to 0.4 , i.e. half as high as the value used for calculating the silo pressure from the overlying $\operatorname{prism}\left(\lambda_{p}=0.8\right)$.

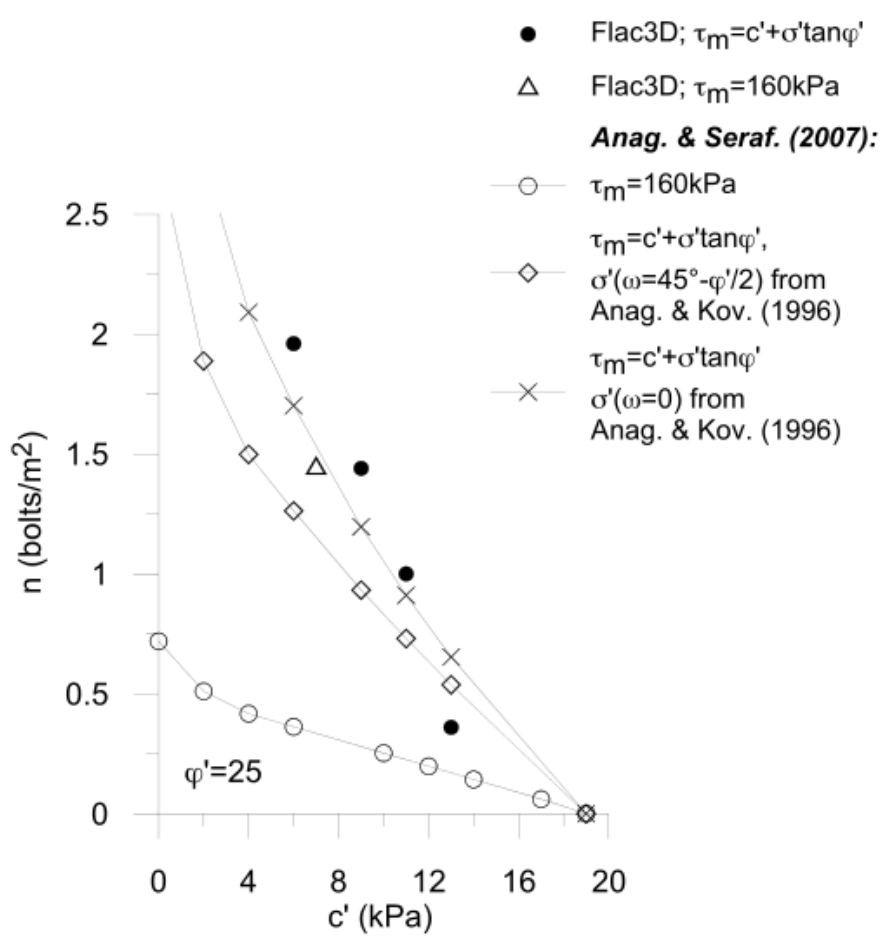

Figure 10 . Necessary bolt density as a function of soil cohesion $\varphi^{\prime}=25^{\circ}$ according to stress analysis with a stress-dependent bond strength and after Anagnostou \& Serafeimidis (2007) under different assumptions concerning the bond strength.

Figure 9 shows the computed bond strength $\tau_{m}$ as a function of the soil cohesion $c^{\prime}$ for two values of the angle $\omega$. (The angle $\omega$ plays a role because it affects the silo pressure and thus the confining stress and the frictional resistance.) The bond strength values calculated in this manner are by a factor of 4 to 5 lower than the initially assumed value of $160 \mathrm{kPa}$ and, combined with the nomograms of Anagnostou \& Serafeimidis (2007), lead to bolt density predictions which are very close to the stress analysis results (Fig. 10). 
The limit equilibrium analysis after Anagnostou \& Serafeimidis (2007) and the numerical stress analysis with the finite difference code FLAC3D provide very close predictions about the stability of an unreinforced tunnel face in dry cohesive frictional soil. The predictions are also absolutely comparable to the predictions obtained by other methods reported in the literature.

The numerical results confirmed that the effects of the lateral earth pressure coefficient, of the dilatancy angle and of the face shape (square, circular, sub-circular) are not important.

In the particular geotechnical and geometrical conditions investigated, the stress analysis of the reinforced face, with modeling of the individual bolts, shows clearly that the failure of the soil around the bolts limits the shear stress developing at the interface bolt - soil and, therefore, the reinforcing effect. For this reason, the bond strength used in the limit equilibrium analyses should consider the shear strength parameters of the ground and the confining stress in the core ahead of the face. Adopting a bond strength based upon the stress distribution after Anagnostou \& Kovári (1994) represents a consistent approach and leads to limit equilibrium results which agree very well with the numerical results.

\section{REFERENCES}

Anagnostou, G., Serafeimidis, K. (2007). The dimensioning of tunnel face reinforcement. ITA-AITES World Tunnel Congress "Underground Space - the $4^{\text {th }}$ Dimension of Metropolises", Prague.

Anagnostou, G., Kovári, K. (1994). The face stability of slurryshield driven tunnels. Tunnelling and Underground Space Technology, 9 (2), 165-174.

Anagnostou, G., Kovári, K. (1996): Face stability conditions with Earth Pressure Balanced shields. Tunnelling and Underground Space Technology, 11 (2), 165-173.

Broere, W. (1998). Face Stability Calculation for a Slurry Shield in Heterogeneous Soft Soils. Tunnels and Metropolises, Sao Paolo, Brazil, 1998, pp. 215-218.

Caquot, A., Kerisel, J. (1956). Traité de mecanique des sols. Gauthier Villars, Paris.

Cornejo, L. (1989). Instability at the face: its repercussions for tunnelling technology. Tunnels and Tunnelling. April, No.21:69-74.

Dias, D. Kastner, R. (2005). Modélisation numérique de l'apport du renforcement par boulonnage du front de taille des tunnels. Can. Geotech. J. 42 (6): 1656-1674.

Leca, E., Dormieux, L. (1990). Upper and lower bound solutions for the face stability of shallow circular tunnels in frictional material. Geotechnique, 40, 581-606.

Mandel, J., Halphen, B. (1974). Stabilité d'une cavitè sphérique souterraine. $3^{\text {rd }}$ Congr. ISRM, 2B, 1028-1032.

Melix, P. 1987. Modellversuche und Berechnungen zur Standsicherheit oberflächennaher Tunnel. Veröff. des Inst. für Boden- und Felsmechanik der Univ. Fridericiana in Karlsruhe, 103 (in German).

$\mathrm{Ng}$, CWW, Lee, GTK (2002). A three-dimensional parametric study of the use of soil nails for stabilising tunnel faces. Computers and Geotechnics. Vol. 29, Issue 8, 673-697.

Ostermayer, H. (1991). Verpreßanker. In GrundbauTaschenbuch 4. Auflage Teil 2. Herausgeber: U. Smoltczyk, Berlin: Ernst \& Sohn.

Kavvadas, M., Prountzopoulos, G. (2009). 3D Analyses of Tunnel Face Reinforcement using Fibreglass Nails. Eur:Tun 2009 Conference. Bochum.

Peila, D. (1994). A theoretical study of reinforcement influence on the stability of a tunnel face. Geotechnical and Geological Engineering, Vol. 12, Num. 3, 145-168.

Ribacchi, R. (1993). Recenti orientamenti nella progettazione statica delle gallerie. $23^{\text {rd }}$ Convegno Nazionale di Geotecnica - Opere in sotterraneo. Rimini.

Terzaghi, K. and Jelinek, R. 1954. Theoretische Bodenmechanik, p. 505. Berlin a.o.: Springer-Verlag (in German).

Vermeer, P.A., Ruse, N., Marcher, T., 2002. Tunnel heading stability in drained ground. Felsbau 20 (6), 8-18.

Yoo, C., Shin, HK. (2003). Deformation behavior of tunnel face reinforced with longitudinal pipes-laboratory and numerical investigation. Tunnelling and Underground Space Technology. Vol. 18, Issue 4, 303-319. 